\title{
Functional impairment and quality of life after rectal cancer surgery
}

\author{
Afectación funcional y calidad de vida tras cirugía de cáncer rectal
}

Laura Mora*, Alba Zarate, Xavier Serra-Aracil, Anna Pallisera, Sheila Serra and Salvador Navarro-Soto

Department of General Surgery and Digestive System, Hospital Universitari Parc Taulí, Universidad Autónoma de Barcelona, Sabadell (Barcelona), Spain

\begin{abstract}
Background: The gold standard of rectal surgery remains total mesorrectal excision (ETM) in which laparoscopy is applied for its advantages. The attempt to avoid $17 \%$ conversion rate implies that transanal techniques are applied. Transanal ETM (TaETM) is performed by experimental groups with good oncological and morbimortality results. Objective: This study determines the quality of life and the anorectal function of these patients. Method: Observational study of two cohorts comparing patients undergoing rectal tumor surgery using TaETM or conventional ETM after a minimum of six months of intestinal transit reconstruction. EORTC-30, EORTC-29 quality of life questionnaires and the anorectal function assessment questionnaire (LARS score) are applied. General variables are also collected. Results: 31 patients between 2011 and 2014: 15 ETM group and 16 TaETM. We do not find statistically significant differences in quality of life questionnaires or in anorectal function. Statistically significant general variables: Ionger surgical time in the TaETM group. Nosocomial infection and minor suture failure in the TaETM group. Conclusion: The performance of TaETM achieves the same results in terms of quality of life and anorectal function as conventional ETM.
\end{abstract}

KEY WORDS: Total excision of the mesorectum. Rectal cancer. Functionality. Quality of life.

\section{Resumen}

Antecedentes: La técnica de referencia de la cirugía rectal sigue siendo la escisión total del mesorrecto (ETM), en la que se aplica la laparoscopia por sus ventajas. El intento de evitar el 17\% de reconversión hace que se apliquen técnicas transanales. La ETM transanal (TaETM) se lleva a cabo por grupos experimentales con buenos resultados oncológicos y de morbimortalidad. Objetivo: Este estudio determina la calidad de vida y la función anorrectal de estos pacientes. Método: Estudio observacional de dos cohortes que compara pacientes intervenidos por tumor rectal mediante TaETM o ETM convencional después de 6 meses mínimo de la reconstrucción del tránsito intestinal. Se aplican los cuestionarios de calidad de vida EORTC-30 y EORTC-29, y el cuestionario de valoración de función anorrectal (LARS score). También se recogen variables generales. Resultados: Entre 2011 y 2014 fueron intervenidos 31 pacientes: 15 en el grupo de ETM y 16 en el de TaETM. No se encuentran diferencias estadísticamente significativas en cuanto a cuestionarios de calidad de vida ni respecto a la función anorrectal. Variables generales estadísticamente significativas: tiempo quirúrgico mayor en el grupo TaETM, e infección nosocomial y fallo de sutura menores en el grupo TaETM. Conclusión: La realización de TaETM obtiene los mismos resultados en cuanto a calidad de vida y función anorrectal que la ETM convencional.

PALABRAS CLAVE: Escisión total del mesorrecto. Cáncer rectal. Funcionalidad. Calidad de vida.

\author{
Correspondence: \\ *Laura Mora López \\ Unidad de Coloproctología (U. de Coloproctología) \\ Servicio de Cirugía General \\ Hospital Universitario Parc Taulí \\ Parc Taulí, $s / n$ \\ 08208 Sabadell, Barcelona, España \\ E-mail: Lmora@tauli.cat
}

Date of reception: 29-11-2017

Date of acceptance: 11-04-2018

DOI: 10.24875/CIRUE.M18000020
Cir Cir. 2018;86:122-129

Contents available at PubMed www.cirugiaycirujanos.com 


\section{Introduction}

In recent times, there have been many technical changes in the field of rectal cancer surgery. Despite the innovations, standard treatment for rectal cancer remains total mesorectal excision (TME), described by Heald ${ }^{1}$ in the 1980s. These changes include the use of laparoscopy, which is also applied in this field. There are studies that support the advantages of its use in rectal surgery, such as the COLOR $\|^{2}$ trial. One of the problems related to the use of laparoscopic techniques in rectal cancer surgery is the rate of conversion to open surgery: $17 \%$ according to the series. The attempt to reduce this conversion rate and make technical improvements in postoperative morbidity and oncological results has led surgical groups to the use of transanal techniques. Transanal TME techniques (TaTME) ${ }^{3,4}$, which in addition take advantage of a natural orifice, the transanal access, are described for extraction of the resection specimen. These techniques can be completely transanal (pure TaTME) ${ }^{5}$ or make use of laparoscopy at some points of the procedure (hybrid TaTME) (3,4,6,7. $^{3}$

Currently, these are established procedures in experienced groups, where short-term postoperative advantages and equivalence have been demonstrated in oncological results ${ }^{3,8}$. The purpose of this study is to determine the quality of life and sphincter function of patients undergoing this technique, and whether these outcomes are equal or better than those in patients operated with open or laparoscopic surgery.

\section{Method}

\section{Type of study}

Observational study with prospective data collection from two cohorts.

\section{Patients}

- Inclusion criteria: patients operated for rectal neoplasm without local or distant disease relapse who underwent TME with low anterior resection (LAR) and protective ileostomy, in whom minimum bowel transit had been reconstructed within 6 months prior to study enrollment. The subjects were divided in two groups: those in whom LAR had been performed by open or laparoscopic route (TME group) and those in whom LAR had been performed via natural orifice transluminal endoscopic surgery (NOTES) (TaTME group).

- Exclusion criteria: impaired higher mental functions, dementia or severe psychiatric disorder, palliative surgery, diagnosed local relapse, inability to answer the questionnaires.

\section{Variables}

- General: demographic (age, gender, ASA grade, tumor-to-anal margin distance, adjuvant chemo-radiotherapy), surgery-related (surgical time, type of anastomosis, protective stoma), anatomopathological (distal margin, circumferential margin, mesorectal quality, number of adenopathies, staging) and postoperative variables (complications according to Clavien-Dindo classification, postoperative stay) were collected.

- Quality of life assessment: all patients underwent a quality of life evaluation according to the Spanish-validated European Organization for Research and Treatment of Cancer questionnaires (EORTC-30 and EORTC-29). These questionnaires have been designed by the EORTC quality of life group to assess cancer patients' quality of life. They consist of different assessment scales: global, functional and symptom scales; all of them scoring from 0 to 100 . On the functionality scales, a higher score reflects better quality of life (excellent: 100-75, good: 74-50, reasonable: 49-25, poor: 24-0). In contrast, for the symptom scales, higher scores reflect an elevated symptom intensity (not at all: 0-24, a little: $25-49$, quite a bit: $50-74$, very much: $75-100)$. Score differences of 5-10 points are considered to reflect small clinical differences, with 10-20 points there are moderate differences, and more than 20 points reflect large differences ${ }^{9,10}$. Administration of the questionnaires was conducted by the same investigator through direct interview and were applied by a group of collaborators blinded to the surgical technique used for each case.

- Sphincter function assessment: all patients were evaluated with the low anterior resection syndrome score (LARS score), also validated into Spanish. The LARS score is a questionnaire designed to assess intestinal dysfunction suffered by patients after LAR, based on the symptoms and their impact on quality of life. It consists of five items related to incontinence for liquid stools, frequency of bowel movements, fractioning 
(clustering) of stools and defecation urgency. It classifies into three categories according to intensity (0-20: no LARS, 21-29: minor LARS, 3042: major LARS) $)^{11,12}$.

\section{Statistics}

The description of quantitative variables was made using mean values and standard deviation when the distribution was regarded as normal. Otherwise, median values, interquartile ranges and ranges were used. Categorical variables were described in absolute numbers and percentages.

In the statistical analysis, for quantitative variables we used Student's t-test and Mann-Whitney's U-test when the criteria to apply the former were not met.

For categorical variables' statistical analysis, we used Pearson's chi-square test.

For the EORTC quality of life scales, the comparison of the different dimensions for each surgical technique was carried out using Student's t test for independent data, after calculating the homogeneity of variances. For the LARS test (which uses a Likert scale), the chi-square test was used, except for the scale that assesses the impact on quality of life, which can be assumed to be a continuous variable, with Student's t-test therefore being used.

An alpha error of 0.05 and a beta error of 0.2 were considered at all times.

The representation of the QLQ-C30 and CQC-CR29 quality of life scales was carried out using radial graphs, where each dimension of the test was placed on a radial line.

Statistical tests results are given for a $p$-value $<0.05$ with its $95 \%$ confidence interval. All different variables were collected in a database in Access format and the results were analyzed using SPSS 21.0. The study was approved by the hospital's Clinical Research Committee (reference: 2014672).

\section{Results}

Thirty-one patients operated between 2011 and 2014 who met the inclusion criteria were studied: 15 in the TME group and 16 in the TaTME group (Table 1).

As for general variables, there were no statistically significant differences in the demographic or anatomopathological variables. There were differences in the surgical time used to perform each technique, with the time required to perform TaTME being statistically significantly longer. There were also differences in postoperative complications-related variables: there were statistically significant differences in favor of the TaTME group in nosocomial complications and suture failure.

The EORTC-C30 questionnaire allows us to compare overall quality of life between the patients included in our study and the baseline values of patients diagnosed with colorectal cancer that have been obtained from EORTC (Fig. 1). In both groups of our study, higher than baseline scores were obtained (74.0 for TaTME and 72.6 for TME vs. 60.7 at baseline). If we compare the scores between both study groups, we observe that the difference is not statistically significant $(p=0.874)$. Statistically significant differences were found for social function between both groups in favor of the TaTME group (89.6 vs. $77.4, p=0.031$ ). Although the other scales assessed by means of the EORTC-C30 questionnaire did not show statistically significant differences, clinically relevant differences were detected in bowel function symptoms. Patients in the TME group had higher scores for both constipation and diarrhea in comparison with the TaTME group (33.3 vs. 22.9 for constipation and 23.8 vs. 14.6 for diarrhea).

When the results obtained using the EORTC-CR29 questionnaire were analyzed, no statistically significant or clinically relevant differences were observed in any of the functional scales for body image, anxiety, weight and sexual interest in men or women (Fig. 2). Regarding the symptom scales, those that also appear in the LARS score questionnaire were analyzed, with statistically significant differences only being observed for pain and abdominal distension symptoms, which were always higher in the TME group than in the TaTME group. TME group patients showed a higher defecation frequency of and impotence, with a clinically relevant difference in the scores (higher than 10 points) (Fig. 3).

The anorectal function was analyzed using the LARS score questionnaire. In the TME group, $60 \%$ of patients had major low anterior resection syndrome (LARS), $13.3 \%$ had minor LARS, and $26.7 \%$ had no LARS. In the TaTME group, $62.5 \%$ of patients had major LARS, $18.8 \%$ minor LARS and $18.8 \%$ had no LARS. There were no statistically significant differences in LARS intensity between both groups (Fig. 4).

\section{Discussion}

The validity of laparoscopic techniques in the management of rectal tumors has been demonstrated 
Table 1. General characteristics of the study population

\begin{tabular}{|c|c|c|c|}
\hline \multirow[t]{2}{*}{ Characteristics } & \multicolumn{2}{|c|}{ Low anterior resection } & \multirow[t]{2}{*}{$p$} \\
\hline & $\begin{array}{l}\text { Open or laparoscopic, } \\
\text { LAR group }(n=15)\end{array}$ & $\begin{array}{c}\text { Transanal, TaTME } \\
\text { group }(n=16)\end{array}$ & \\
\hline \multicolumn{4}{|l|}{ Demographic } \\
\hline Age & 64,00 & 59,94 & 0.439 \\
\hline Gender & & & 0.704 \\
\hline Males & 10 & 12 & \\
\hline Females & 5 & 4 & \\
\hline ASA & & & 0.456 \\
\hline 1 & 0 & 0 & \\
\hline$\|$ & 9 & 11 & \\
\hline III & 6 & 4 & \\
\hline IV & 0 & 1 & \\
\hline Tumor-anal margin distance & 7,93 & 7,44 & 0.723 \\
\hline Neoadjuvance & 11 & 7 & 0.247 \\
\hline \multicolumn{4}{|l|}{ Surgical } \\
\hline Surgical time & 114,29 & 251,88 & 0.000 \\
\hline Anastomosis type & & & 0.367 \\
\hline Mechanical end-to-end & 15 & 16 & \\
\hline Protective stoma (ileostomy) & 15 & 16 & 0 \\
\hline \multicolumn{4}{|l|}{ Anatomopathological } \\
\hline Distal margin & 2,16 & 2,43 & 0.579 \\
\hline Circumferential margin & 1,30 & 15,44 & 0.395 \\
\hline Complete & 14 & 16 & 0.484 \\
\hline Partial & 0 & 0 & 0 \\
\hline Incomplete & 1 & 0 & \\
\hline \multicolumn{4}{|l|}{ No. of adenopathies } \\
\hline Stage & $1,07 / 12,79$ & $2,25 / 13,56$ & \\
\hline 0 & 3 & 0 & 0.953 \\
\hline I & 6 & 5 & 0.143 \\
\hline$\|$ & 3 & 7 & \\
\hline III & 3 & 2 & \\
\hline \multicolumn{4}{|l|}{ Postoperative complications } \\
\hline Medical & $26.7 \%$ & $6.7 \%$ & 0.122 \\
\hline Surgical & $20 \%$ & $26.7 \%$ & 0.74 \\
\hline Nosocomial & $60 \%$ & $13.3 \%$ & 0.006 \\
\hline Suture failure & $60 \%$ & $13.3 \%$ & 0.006 \\
\hline Hospital length of stay (days) & 5.07 & 7.75 & 0.308 \\
\hline
\end{tabular}

since long time ago, both with respect to surgical morbidity and mortality and to oncological results, in comparison with classical procedures, ${ }^{3}$ with TME always being maintained as the reference for all procedures, regardless of the type of approach ${ }^{1}$. With the advent of transanal techniques, it has been possible to advance even further in the improvement of the use of laparoscopy in the treatment of rectal tumors ${ }^{3,4}$. In addition to demonstrating that it is technically possible, the oncological results of these techniques have also been shown to be comparable to classically labeled standards ${ }^{4}$. With the results of this study, although with a small sample, a lower number of postoperative complications can be observed in the TaTME group than in the LAR group. Whether the use of these techniques equals or improves the results thus far obtained in terms of functionality and quality of life remains to be demonstrated.

We know that the use of TME to treat rectal tumors is associated with rates of genitourinary alterations, sexual dysfunction and anorectal functionality that are not negligible. Recent studies report $20-30 \%$ of genitourinary alterations and sexual dysfunction in these patients ${ }^{13,14}$. Rates ranging from 10 to $30 \%$ in anorectal functionality alterations are also described ${ }^{15,16}$. All this entails quality of life alterations.

TME allows very good oncological results in terms of survival in patients with rectal cancer ${ }^{1}$. It is also important to establish which procedures performed using TME can lead to quality of life worsening or improvement. We believe it is important to know which are the functional results offered by technological 

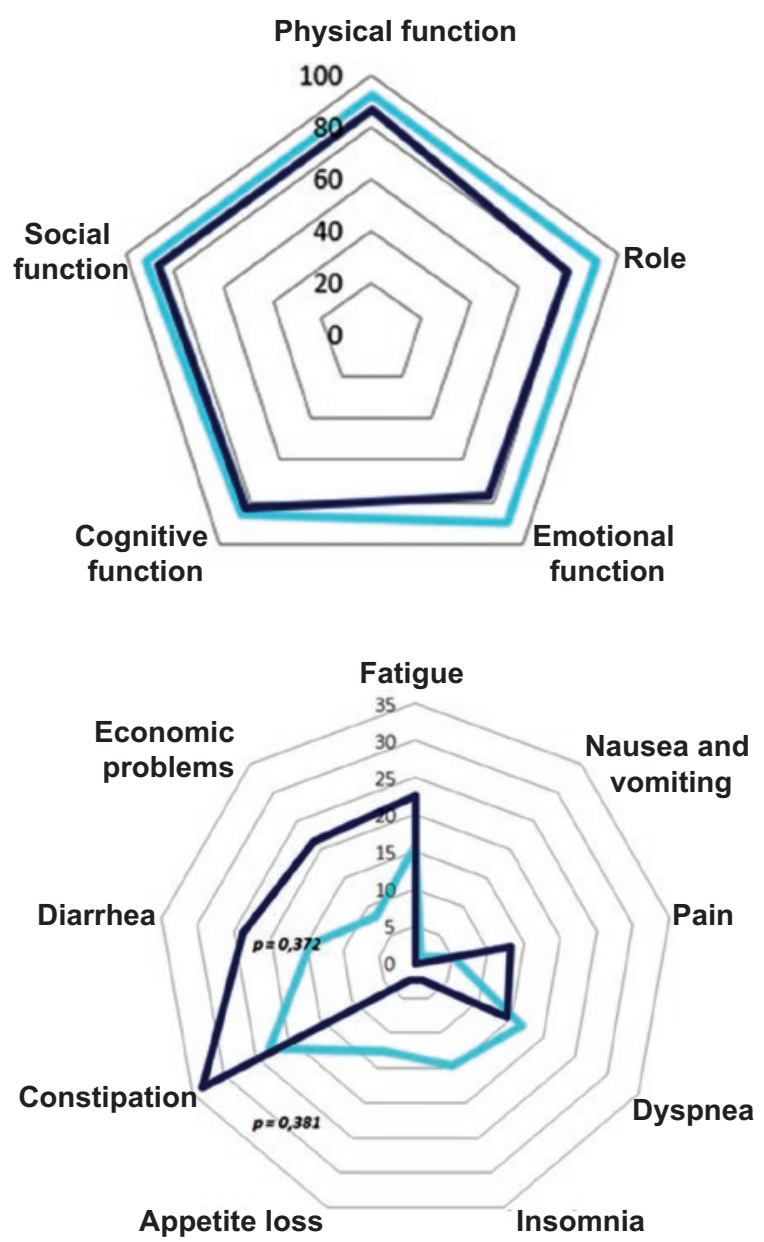

\begin{tabular}{lccc}
\hline & NOTES & RAB & $\mathbf{p}$ \\
\hline Quality of life scale & & & \\
Global quality of life & 73,96 & 72,62 & 0,874 \\
& & & \\
Functional scales & 92,5 & 86,67 & 0,273 \\
Physical function & 91,67 & 79,76 & 0,255 \\
Role function & 89,58 & 77,38 & 0,031 \\
Emotional function & 85,42 & 83,33 & 0,775 \\
Cognitive function & 91,67 & 86,90 & 0,604 \\
Social function & & & \\
& & & \\
Symptom scale & 15,97 & 22,61 & 0,462 \\
Fatigue & 1,04 & 0 & 0,359 \\
Nausea and vomiting & 5,20 & 13,09 & 0,235 \\
Pain & 16,67 & 14,28 & 0,814 \\
Dyspnea & 14,58 & 21,42 & 0,426 \\
Insomnia & 12,5 & 2,38 & 0,190 \\
Appetite loss & 22,92 & 33,33 & 0,381 \\
Constipation & &
\end{tabular}

Figure 1. EORTC CR-30 questionnaire. Global and functional scale. Statistical analysis: Student's t-test.

advances. For this reason, we have carried out this study, to find out if patients who are being treated by means of TaTME experience quality of life variations in comparison with patients treated with standard laparoscopic LAR. It is a retrospective cohort study, and performing a randomization or group sample calculation has therefore not been possible.

General characteristics of the study groups enable to see that, despite the limitations of the study, these groups are similar in terms of demographic variables. There are no differences regarding mean age or gender; in both groups, ASA II and III patients are predominant and, regarding the tumors, mean distance of the lesion to the anal margin is similar in both groups, as well as neoadjuvant administration. With regard to surgical characteristics, all anastomoses were end-toend in both groups and all patients underwent protective ileostomy. In contrast, there are statistically significant differences in the surgical time used for each technique: transanal surgery (TaTME group) requires more surgical time than open or laparoscopic surgery. Possibly, these differences can be improved, since these are transanal surgery initial experiences. Anatomopathological characteristics were similar in both groups. There were also statistically significant differences in postoperative complications. There were more nosocomial complications and more suture failures in the open or laparoscopic TME group. It is a small number of patients, and this is not the purpose of the study either, but the transanal technique appears to be safer in this regard.

In our sample, according to EORTC-30, which is a general questionnaire about quality of life assessment, we see that both groups show very similar values and in both cases better than the reference values offered by EORTC 9 . When we analyzed the specific questionnaire (EORTC-29), we observed that there were no differences between both groups and that there are only clinical differences in terms of pain and abdominal bloating, which are worse in the TME group (difficult-to-interpret data).

Regarding the anorectal function, which we assessed with the LARS questionnaire, there were no differences between both groups and the values were comparable to the results obtained by other authors ${ }^{17}$. Therefore, we can say that using a proctoscope to perform TaTME does not appear to have an impact on anorectal function, as we have already shown in a group of patients undergoing local surgery for rectal lesions ${ }^{18}$.

There is limited literature about the impact on quality of life and anorectal function after the performance of a TaTME procedure. Similar results to ours were obtained in a group of 25 patients undergoing transanal sigmoidectomy, even with manometric data 


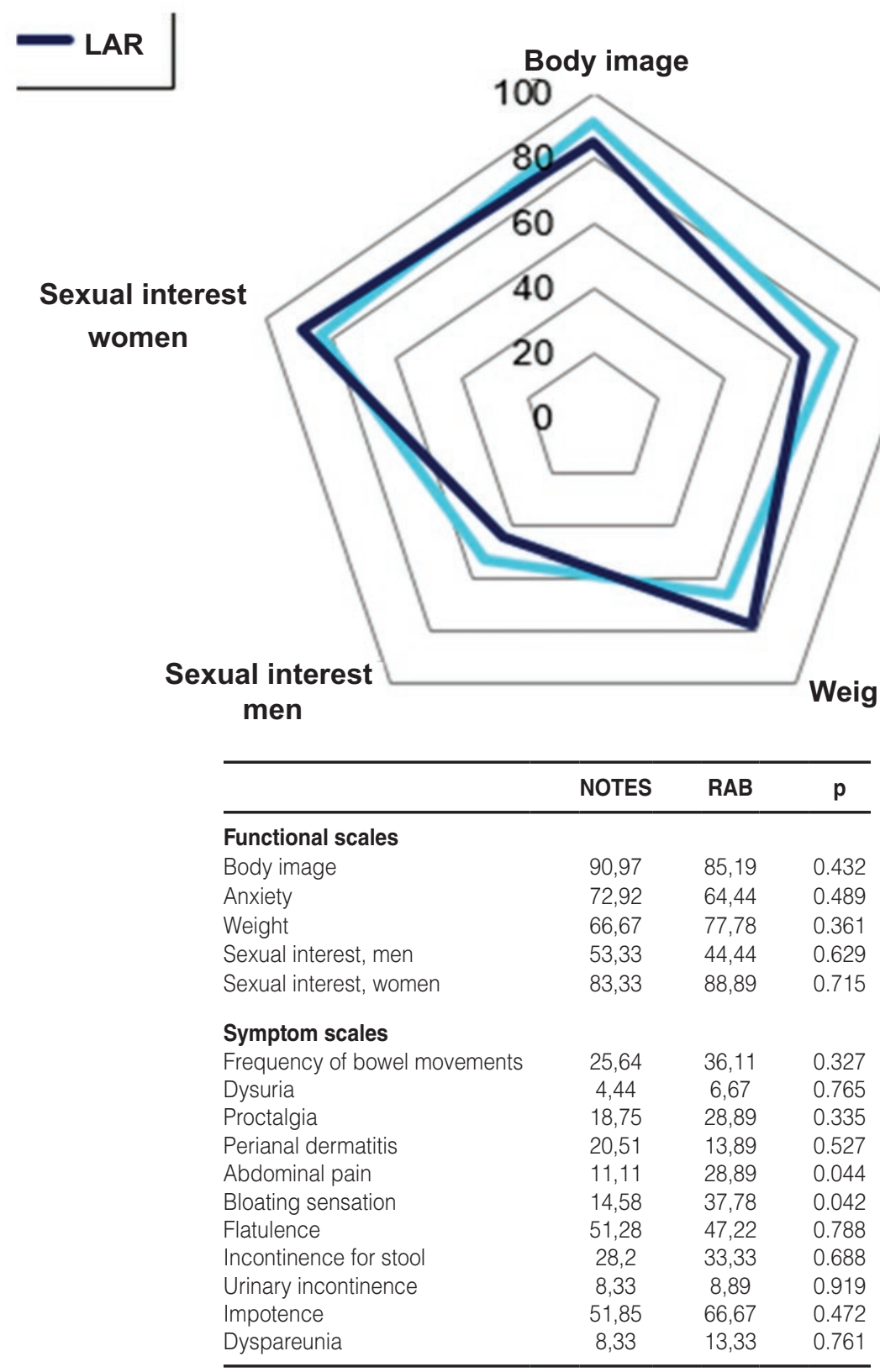

Figure 2. EORTC CR-29 questionnaire. Function scales.

showing that they do not experience variations in the anorectal function or that these are transient and do recover ${ }^{19}$. There is a study assessing the quality of life of a group of 30 patients undergoing TaTME, where the same questionnaires used in this work were applied twice: at one month and at 6 months postoperatively ${ }^{20}$. They show some differences in terms of results, with a higher percentage of deterioration in the LARS score that in our group of patients undergoing TaTME. Despite the limitations referred by the authors themselves, they conclude that the quality of life of patients undergoing TaTME is not different from that of those who undergo conventional TME.
Our study has some limitations: it has few patients in each group, there is no randomization and, since it is a retrospective study, making a sample calculation was not possible to. Ours' are groups where homogenization was not possible.

With the obtained results, taking into account the study limitations, we can say that, up to this moment, the results in terms quality of life and anorectal function in patients undergoing TaTME are not different from those obtained in patients undergoing conventional TME. For the moment, we cannot say that the technique causes a worsening of quality of life or anterior resection syndrome in patients undergoing the procedure. 


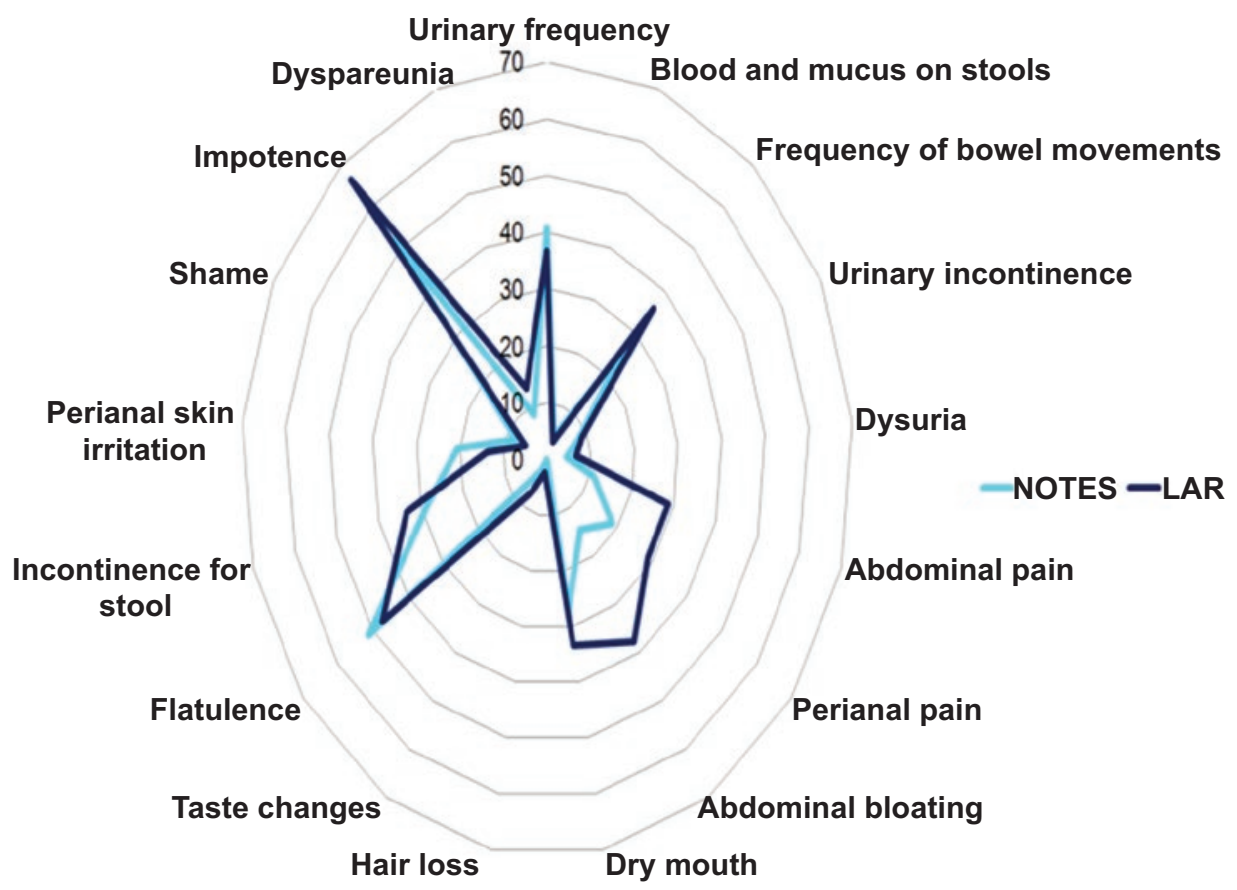

Figure 3. EORTC CR-29 questionnaire. Symptom scale.

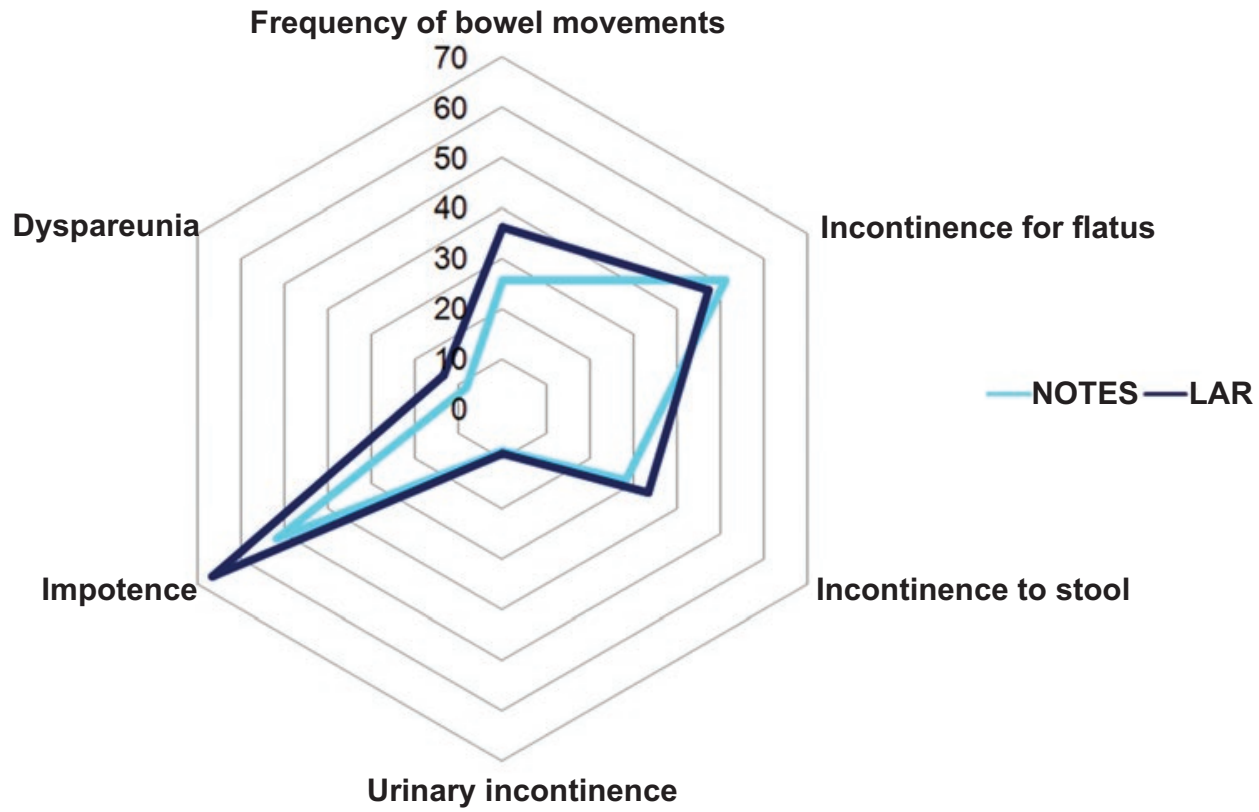

Figure 4. Analysis of EORTC CR-29 symptoms appearing in the LARS questionnaire.

LAR ( $\square$ ): Transanal LAR, TaTME group

NOTES ( ): Open or laparoscopic LAR, TME group

Statistical analysis: chi-square test.

However, prospective and randomized studies will be necessary in order to confirm the results obtained so far.

\section{Conflicts of interest}

None of the authors has any type of conflicts of interest relevant to the publication of this work.

\section{References}

1. Heald RJ. The "HolyPlane" of rectal surgery. J R Soc Med. 1988;8:503-8.

2. Van der Pas MH, Haglind E, Cuesta MA, Lacy AM, Hop WC, Bonjer HJ, et al. Colorectal cancer Laparoscopic or Open Resection II (COLOR II) Study Group. Laparoscopic versus open surgery for rectal cancer (COLOR II): shortterm outcomes of a randomisedphase 3 trial. Lancet Oncol. 2013;14:210-8.

3. Sylla P, Rattner DW, Delgado S, Lacy AM. NOTES transanal rectal cancer resection using transanal endoscopic microsurgery and laparoscopic assistance. Surg Endosc. 2010;24:1205-10. 
4. Serra-Aracil X, Mora-López L, Casalots A, Pericay C, Guerrero R, Navarro-Soto S. Hybrid NOTES: TEO for transanal total mesorrectal excision: intracorporeal resection and anastomosis. Surg Endosc. 2016;30:346-54.

5. Leroy J, Barry BD, Melani A, Mutter D, Marescaux J. No-scar transanal total mesorrectal excision: the last step to pure NOTES for colorectal surgery. JAMA. Surg. 2013;148:226-30.

6. Horgan S, Cullen JP, Talamini MA, Mintz Y, Ferreres A, Jacobsen GR, et al. Natural orifice surgery: initial clinical experience. Surg Endosc. 2009;23:1512-8.

7. Lacy AM, Rattner DW, Adelsdorfer C, Tasende MM, Fernández M, Delgado S, et al. Transanal natural orifice transluminal endoscopic surgery (NOTES) rectal resection: "down-to-up" total mesorectal excision (TME) short-term outcomes in the first 20 cases. Surg Endosc. 2013;27:3165-72.

8. Fernández-Hevia M, Delgado S, Castells A, Tasende M, Momblan D, Díaz del Gobbo G, et al. Transanal total mesorectal excision in rectal cancer: short-term outcomes in comparison with laparoscopic surgery. Ann Surg. 2015;261:221-7.

9. Arraras Urdaniz JI, Villafranca Iturre E, Arias de la Vega F, Domínguez Domínguez MA, Lainez Milagro N, Manterola Burgaleta A, et al. The EORTC quality of life questionnaire QLQ-C30 (version 3.0). Validation study for Spanish prostate cancer patients. Arch Esp Urol. 2008;61:949-54

10. Arraras J, Suárez J, Arias de la Vega F, Vera R, Asín G, Arrazubi V et al. The EORTC Quality of Life questionnaire for patients with colorectal cancer: EORTC QLQ-CR29 validation study for Spanish patients. Clin Transl Oncol. 2011;13:50-6.

11. Emmertsen KJ, Laurberg S. Low anterior resection syndrome score: development and validation of a symptom-based scoring system for bowel dysfunction after low anterior resection for rectal cancer. Ann Surg. 2012;255:922-8.
12. Juul T, Ahlberg M, Biondo S, Emmertsen KJ, Espin E, Jiménez LM, et al. International validation of the low anterior resection syndrome score. Ann Surg. 2014;259:728-34.

13. Kneist $\mathrm{W}$, Junginger $\mathrm{T}$. Residual urine volume after total mesorectal excision: an indicator of pelvic autonomic nerve preservation? Results of a case-control study. Colorectal Dis. 2004;6:432-7.

14. Shah EF, Huddy SPJ. A prospective study of genito-urinary dysfunction after surgery for colorectal cancer. Colorectal Dis. 2001;3:122-5.

15. Maas CP, Moriya Y, Steup WH, Klein Kranenbarg E, van de Velde CJ. A prospective study on radical and nerve-preserving surgery for rectal cancer in the Netherlands. Eur J Surg Oncol. 2000;26:751e757.

16. Enker WE, Merchant N, Cohen AM, Lanouette NM, Swalon C, Guillem J, et al. Safety and efficacy of low anterior resection for rectal cancer: 681 consecutive cases from a specialty service. Ann Surg. 1999;230:544-52; discussion 552-4.

17. Bregendahl S, Emmertsen KJ, Lous J, Laurberg S. Bowel dysfunction after low anterior resection with and without neoadjuvant therapy for rectal cancer: a population-based cross-sectional study. Colorectal Dis. 2013;15:1130-9.

18. Mora López L, Serra Aracil X, Hermoso Bosch J, Rebasa P, Navarro Soto S. Study of anorectal function after transanal endoscopic surgery. Int J Surg. 2015;13:142-7.

19. Steinemann DC, Zerz A, Germann S, Lamm SH. Anorectal function and quality of life after transrectal rigid-hybrid natural orifice transluminal endoscopic sigmoidectomy. J Am Coll Surg. 2016;223:299-307.

20. Koedam TW, van Ramshorst GH, Deijen CL, Elfrink AK, Meijerink WJ, Bonjer HJ, et al. Transanal total mesorectal excision (TaTME) for rectal cancer: effects on patient-reported quality of life and functional outcome. Tech Coloproctol. 2017;21:25-33. 